\title{
Influence of Nitrided Layer on the Properties of Carbon Coatings Produced on X105CrMo17 Steel Under DC Glow-Discharge Conditions
}

\author{
Tomasz BOROWSKI *, Maciej OSSOWSKI, Piotr KOWALCZYK, Maciej DUBEK, \\ Agnieszka BROJANOWSKA, Krzysztof ROŻNIATOWSKI
}

\author{
Warsaw University of Technology, Faculty of Materials Science and Engineering, ul. Wołoska 141, 02-507 Warsaw, \\ Poland \\ cross $^{\text {ref }}$ http://dx.doi.org/10.5755/j01.ms.22.3.7532
}

Received 05 July 2014; accepted 07 April 2016

\begin{abstract}
In most cases, machine components, which come in contact with each other, are made of steel. Common steel types include 100Cr6 and X105CrMo17 are widely used in rolling bearings, which are subjected to high static loads. However, more and more sophisticated structural applications require increasingly better performance from steel. The most popular methods for improving the properties of steel is carburisation or nitriding. Unfortunately, when very high surface properties of steel are required, this treatment may be insufficient. Improvement of tribological properties can be achieved by increasing the hardness of the surface, reducing roughness or reducing the coefficient of friction. The formation of composite layers on steel, consisting of a hard nitride diffusion layer and an external carbon coating with a low coefficient of friction, seems to be a prospect with significant potential. The article describes composite layers produced on $\mathrm{X} 105 \mathrm{CrMo} 17$ steel and defines their morphology, surface roughness and their functional properties such as: resistance to friction-induced wear, coefficient of friction and corrosion resistance. The layers have been formed at a temperature of $370^{\circ} \mathrm{C}$ in successive processes of: nitriding in low-temperature plasma followed by deposition of a carbon coating under DC glow-discharge conditions. An evaluation was also made of the impact of the nitrided layers on the properties and morphology of the carbon coatings formed by comparing them to coatings formed on non-nitrided $\mathrm{X} 105 \mathrm{CrMo} 17$ steel substrates. A study of the surface topography, adhesion, resistance to friction-induced wear and corrosion shows the significant importance of the substrate type the carbon coatings are formed on.

Keywords: hybrid technology, carbon coating, nitrided layer, friction coefficient, corrosion resistance.
\end{abstract}

\section{INTRODUCTION*}

DLC (diamond-like carbon) or NCD (nanocrystalline diamond) carbon coatings have been extensively tested for over 30 years [1], but it is only recently that they have found application in industry. Many companies now offer diamond-like coatings for various applications including metalworking (drills, cutters), in the automotive industry (engine parts, hydraulic parts), in medicine (implants, medical tools), in optics (lasers), electronics (a protective and self-greasing layer in hard drives, an insulating layer in microelectronics) and for sliding and rolling elements (bearings, bushes, rollers) [2]. The wide interest in these coatings derives from their high resistance to wear by friction and corrosion, good hardness, as well as chemical inertness and the biocompatibility of these materials [3-5]. This outstanding combination of different properties gives this material very high potential in tribological applications. Carbon coatings are characterised by a very low coefficient of friction compared to other coatings used to cover metallic materials [2].

Out of the different methods of producing diamondlike coatings, we can distinguish the following techniques: RF CVD (radio frequency chemical vapour deposition), MW CVD (microwave CVD), PVD (physical vapour deposition), IBAD (ion beam assisted deposition) and PLD (pulsed laser deposition) [3-7]. By means of the methods

\footnotetext{
* Corresponding author. Tel.: +48-22-234-87-02.

E-mail address: borowski.tomasz@wp.pl (T. Borowski)
}

presented above, coatings with various structures and properties can be obtained. All the methods, which make it possible to deposit carbon coatings, are assisted to a greater or lesser degree by plasma. Classic methods of steel surface treatment such as nitriding or carbonitriding are successfully carried out in processes involving DC or pulsed discharge $[8,9]$. The initial tests carried out so far, suggest that carbon coatings can also be deposited using this type of discharge. There are no literature reports on carbon coatings produced by means of this method, thus making the technology, which is under development, new and original. Carbon coating deposition in conditions of glow-discharge nitriding takes place in an atmosphere of methane and nitrogen at a temperature, which does not exceed $400{ }^{\circ} \mathrm{C}$. This means that the tested coatings can be produced on steel elements without a significant drop in the hardness of their core. An additional advantage of this method is the possibility to carry out (in one technological process) nitriding or carbonitriding, and then, by changing the composition of the mixture of gas and pressure in the working chamber, a carbon coating can be deposited on the nitrided or carbonitrided substrate.

Carbon coatings are characterized by relatively high residual stress reaching values of up to several GPa [2]. Too high levels of compressive tension found in these coatings can lead to cracks even during their deposition, and even more so in the course of their tribological use. A forward-looking solution seems to be the use of an intermediate diffusive layer, characterised by a gradient structure [4]. 
The aim of the study was to characterize a layer with a complex structure deposited on X105CrMo17 by means of a hybrid method combining deposition of a carbon coating under DC glow-discharge conditions following glowdischarge plasma nitriding, and to examine the influence of the impact of the diffusion layer on the morphology and properties of the coatings obtained.

\section{TEST METHODOLOGY}

Martensitic X105CrMo17 corrosion resistant steel, often used for bearings, was used as a substrate in the process of coating production by means of the hybrid method. The composition of X105CrMo17 steel according to Polish standard PN-71/H-86020 is shown in Table 1. The steel was tempered at a temperature of $1100{ }^{\circ} \mathrm{C}$ and was then cooled in oil.

Table 1. The concentration of elements in $\mathrm{X} 105 \mathrm{CrMo} 17$ steel, $\% \mathrm{w} / \mathrm{w}$

\begin{tabular}{|c|c|c|c|c|c|c|c|c|}
\hline $\mathrm{C}$ & $\mathrm{Cr}$ & $\mathrm{Ni}$ & $\mathrm{P}$ & $\mathrm{S}$ & $\mathrm{Mn}$ & $\mathrm{Si}$ & $\mathrm{Ti}$ & $\mathrm{Cu}$ \\
\hline 1.0 & 18 & $\leq 0.6$ & $\leq 0.04$ & $\leq 0.03$ & $\leq 0.8$ & $\leq 0.8$ & $\leq 0.3$ & $\leq 0.3$ \\
\hline
\end{tabular}

The layers were formed using three variants of surface treatment on samples measuring: $25 \mathrm{~mm}$ in diameter and $6 \mathrm{~mm}$ in thickness. The first variant is plasma nitriding carried out at $370{ }^{\circ} \mathrm{C}(\mathrm{PN} 370)$ at a pressure of 2 mbar, in a mixture of gases $\mathrm{N}_{2}: \mathrm{H}_{2}=1: 1$ for $21.6 \mathrm{ks}$. In the second and third variant, the carbon coatings were produced in a process with a temperature of $370{ }^{\circ} \mathrm{C}$ in a mixture of gases $\mathrm{CH}_{4}: \mathrm{N}_{2}=10: 1$ for $1.8 \mathrm{ks}$ at 4.5 mbar. The carbon coating was produced on a layer which underwent plasma nitriding (PN370-C) and on steel in initial state (IS-C). The layer nitrided at $370{ }^{\circ} \mathrm{C}$ is characterised by the most optimal parameters in terms of the improvement of wear and corrosion resistance. Prior to the processes, all the samples were ground using 400, 600, 800, 1000 and 1200-grit sandpaper and then polished using a suspension of $2.5 \mu \mathrm{m}$ of $\mathrm{Al}_{2} \mathrm{O}_{3}$.

Observations of the morphology of the surface of the layers was carried out using a Hitachi S-3500N scanning electron microscope (SEM) at an acceleration voltage of $V_{\text {acc }}=15 \mathrm{kV}$. Examinations of the chemical composition of the coating were carried out by means of energy dispersive spectroscopy (EDS) using a Thermo Noran spectrometer. The phase composition of $\mathrm{X} 105 \mathrm{CrMo} 17$ steel was analysed with a Bruker D8 ADVANCE diffractometer using filtered $\mathrm{Cu} \mathrm{K} \alpha(\lambda=0.154056 \mathrm{~nm})$ radiation at room temperature. Microhardness tests were carried out using Vickers method on a ZWICK Materialprufung 3212007 hardness meter under a load of $200 \mathrm{~g}$ (HV0.2). Surface topography tests were performed with a WYKO NT9300 optical profilometer. In each of the tests, the mean values of the following parameters were calculated: average arithmetic roughness $\left(R_{\mathrm{a}}\right)$, root mean square roughness $\left(R_{\mathrm{q}}\right)$, five of the highest peaks and five of the lowest depressions $\left(R_{\mathrm{z}}\right)$. The distance between the highest and the lowest point $\left(R_{\mathrm{t}}\right)$ were also calculated.

Tests of the resistance to wear by friction were carried out using the "ball-on-disk" method by means of an ITE Radom T-21 tribotester. A ball made of $\mathrm{Al}_{2} \mathrm{O}_{3}$ ceramic alumina was used each time, which before every measurement, was degreased with acetone. Before the tests, the surface of the samples did not undergo any cleaning. The tests were conducted at an ambient temperature of $\left(23 \pm 3^{\circ} \mathrm{C}\right)$. Resistance to wear by friction was carried out at a unit load of $10 \mathrm{~N}$, and the total number of rotations in the test amounted to 3300. During the test, a wear force was achieved, which was calculated into the wear coefficient. The wear tracks formed on the samples were analysed using an optical profilometer. The study was carried acc. standard ASTM G 99-05.

The adhesion of the layer was evaluated by means of the Scratch Test. This method involves scratching the coating using a diamond tip and registering the friction forces, wear coefficient and acoustic emission. Afterwards, the critical forces, as a result of which coating damage occurs, were determined. The study was conducted using a CSM Revetest device equipped with an optical microscope which is used for scratch observations. The test was carried out using an increasing load value from 1-10 N and 1-50 N applied with a Rockwell C tip. Scratches were made over a distance of $5 \mathrm{~mm}$ with a speed of $1.8 \mathrm{~N} / \mathrm{min}$.

Corrosion resistance tests were carried out by means of the potentiodynamic method using an Eco Chemie B.V. AutoLab PGSTAT100 system for electrochemical tests. The tests were carried out using a three-electrode setup in an environment of $0.5 \mathrm{M} \mathrm{NaCl}$. For reference purposes a saturated calomel electrode $\left(\mathrm{Hg} / \mathrm{Hg}_{2} \mathrm{Cl}_{2} / \mathrm{KCl}\right)$ was used. Its potential in relation to the hydrogen electrode was $+240 \mathrm{mV}$, whereas the auxiliary electrode was made of platinum. For each of the materials, the corrosion tests were carried out three or four times, and the average results for each sample are listed in the paper. Potentiodynamic tests were conducted from a potential of ca. $200 \mathrm{mV}$ lower than the corrosion potential to $+750 \mathrm{mV}$ at a sweep rate of $0.2 \mathrm{mV} / \mathrm{sec}$. The curves obtained were used to determine the polarisation resistance $R_{\text {pol }}$ values using the Stern method. The corrosion potential $\mathrm{E}_{\mathrm{corr}}$ and the corrosion current densities $i_{\text {corr }}$ were measured by means of Tafel plots, taking into account the conditions of applicability of these methods.

\section{RESULTS AND DISCUSSION}

Fig. 1 shows two surfaces: of plasma nitrided steel (PN370) and of steel in initial state (IS). As a result of the diffusion nitriding process, without forming a compounds zone, strong residual stress levels appear in the top layer causing the deformation of the crystal lattice, sliding at the grain boundary and the formation of a characteristic relief zone revealing the structure of the top layer (Fig. $1 \mathrm{~b}$ ). It can be easily noticed that the quantity, location and size of carbides on the surface of X105CrMo17 steel (IS) (Fig. 1 a) corresponds to the distribution and size of carbides on the nitrided surface (PN370) (Fig. $1 \mathrm{~b}$ ). The secondary carbides $(\mathrm{Cr}, \mathrm{Fe})_{23} \mathrm{C}_{6}$ and $(\mathrm{Cr}, \mathrm{Fe})_{7} \mathrm{C}_{6}$ found in $\mathrm{X} 105 \mathrm{CrMo} 17$ steel, nitride in a different way than the rest of the matrix and can create new compounds with a slightly different composition and crystal structure (lattice parameter) for example $(\mathrm{Cr}, \mathrm{Fe})_{23}(\mathrm{C}, \mathrm{N})_{6}$ or $(\mathrm{Cr}, \mathrm{Fe})_{7}(\mathrm{C}, \mathrm{N})_{6}$.

The hardness of the nitrided layer reached a value of ca. $870 \mathrm{HV} 0.2$ and was over $200 \mathrm{HV} 0.2$ harder than steel in initial state (660 HV 0.2). 


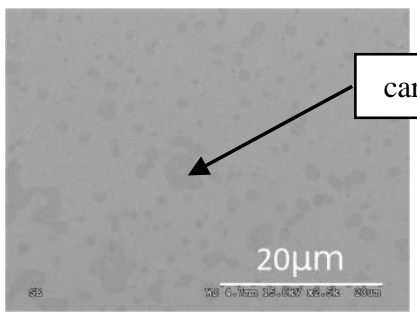

a

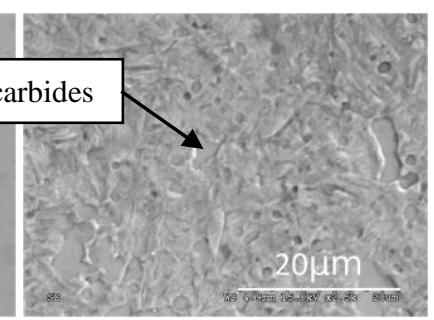

$\mathrm{b}$
Fig. 1. a-morphology of the surface of $\mathrm{X} 105 \mathrm{CrMo} 17$ steel in initial state (IS); b-after plasma nitriding (PN370) b); 2500x magnification

The surface which underwent glow-discharge nitriding $\left(T=370{ }^{\circ} \mathrm{C}, t=21.6 \mathrm{ks}\right)$, on which a carbon coating was subsequently formed $\left(T=370^{\circ} \mathrm{C}, t=1.8 \mathrm{ks}\right)(\mathrm{PN} 370-\mathrm{C})$ is shown in Fig. 2 b. On the surface of the coating, numerous heterogeneous structures in the form of small and large cavities can be seen. The surface of the carbon coating (PN370-C) has a similar topographic nature to that of the nitrided steel (PN370). It appears to reflect the topography of the layer, which was previously nitrided. The outline of a number of $2-5 \mu \mathrm{m}$ carbides found on the nitrided steel surface (PN370) (Fig. 1 b) is also observed on the surface of the carbon coating (PN370-C) (Fig. 2 b). On the surface of the applied carbon coating, characteristic depressions remain in places where the carbides are present. It is thus fair to say that the distribution and size of the carbides in $\mathrm{X} 105 \mathrm{CrMo} 17$ steel affects the formation and the microstructure of the nitrided layer, the surface of which is reflected by the carbon coating which has been subsequently formed.

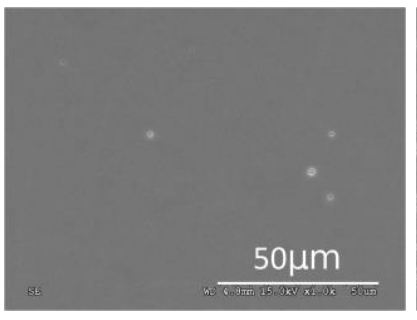

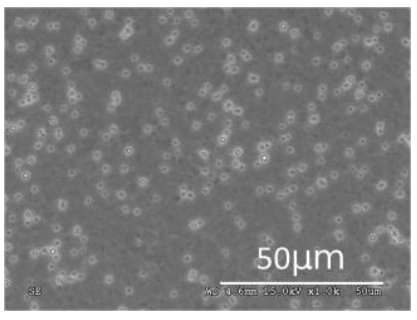

b
Fig. 2. a-morphology of the surface of $\mathrm{X} 105 \mathrm{CrMo} 17$ steel in initial state and after deposition of a carbon coating (IS$\mathrm{C}) ; \mathrm{b}-$ of the surface of $\mathrm{X} 105 \mathrm{CrMo} 17$ after plasma nitriding and deposition of a carbon coating (PN370-C); 1000x magnification

The surface of the X105CrMo17 steel sample in initial state, on which a carbon coating was produced at $370{ }^{\circ} \mathrm{C}$, is illustrated in Fig. 2 a (IS-C). The surface is characterized by a much smaller number of defects compared to the sample, which before the deposition of a carbon coating was nitrided by means of the glow-discharge method (PN370-C) (Fig. 2 b). This has to do with the fact that the carbon coating replicates the surface of the sample, and since the surface was polished and is smooth (no relief) then the carbon coating produced on it is characterised by a higher level of uniformity and better quality.

The surface roughness parameters of the layers and coatings produced on the steel are shown in Table 2. The carbon coating produced on X105CrMo17 steel in initial state (IS-C) was characterised by a roughness of $R_{\mathrm{a}}=30 \mathrm{~nm}$, while the layer produced on the previously nitrided layer (PN370-C) showed a roughness of
$R_{\mathrm{a}}=69 \mathrm{~nm}$. These roughness values are similar to those of the surfaces, on which coatings were produced (initial state $R_{\mathrm{a}}=16 \mathrm{~nm}$, layer obtained after nitriding $R_{\mathrm{a}}=62 \mathrm{~nm}$ ). This demonstrates that the surface topography was replicated by the carbon coatings. Other parameters $\left(R_{\mathrm{q}}, R_{\mathrm{z}}, R_{\mathrm{t}}\right)$ present a similar correlation.

Table 2. Surface roughness of $\mathrm{X} 105 \mathrm{CrMo} 17$ steel in initial state and with formed layer and coatings

\begin{tabular}{|c|c|c|c|c|}
\hline Sample & $R_{\mathrm{a}}, \mathrm{nm}$ & $R_{\mathrm{q}}, \mathrm{nm}$ & $R_{\mathrm{z}}, \mathrm{nm}$ & $R_{\mathrm{t}}, \mathrm{nm}$ \\
\hline IS & 16 & 21 & 314 & 601 \\
\hline IS-C & 30 & 57 & 1860 & 2947 \\
\hline PN370 & 62 & 85 & 1293 & 1533 \\
\hline PN370-C & 69 & 106 & 2840 & 3660 \\
\hline
\end{tabular}

A quantitative analysis of the chemical composition was carried out on the nitrided sample modified with a carbon coating (PN370-C). The results of the surface analysis in characteristic areas (Fig. 3) is summarised in Table 3. The applied coating, in places that correspond to points 2 and 4, is a lot thinner because these places have more than $50 \%$ w/w of $\mathrm{Fe}$ and over $10 \%$ w/w of $\mathrm{Cr}$, in contrast with the remaining areas (points 1, 3 and 5) where the content of these elements is limited to a mere few percent. It is also clearly observed that points 2 and 4 correspond to the depressions of the carbon coating that replicated the surface after nitriding, thus these places probably correspond to the carbides of X105CrMo17 steel.

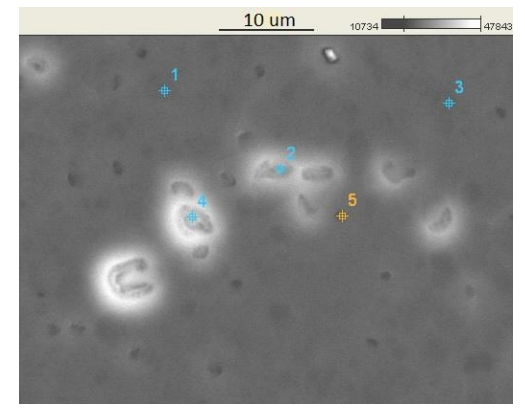

Fig. 3. Areas of EDS spectrometer analysis of the chemical composition of $\mathrm{X} 105 \mathrm{CrMo} 17$ steel surface after plasma nitriding and deposition of a carbon coating (PN370-C)

Table 3. Chemical composition in the test points on the surface of $\mathrm{X} 105 \mathrm{CrMo} 17$ steel after plasma nitriding and deposition of a carbon coating (PN370-C)

\begin{tabular}{|c|c|c|c|c|c|c|c|}
\hline \multirow{2}{*}{ Point } & \multicolumn{7}{|c|}{ Element, \% w/w } \\
\cline { 2 - 8 } & $\mathrm{C}$ & $\mathrm{N}$ & $\mathrm{Si}$ & $\mathrm{Cr}$ & $\mathrm{Mn}$ & $\mathrm{Fe}$ & $\mathrm{Ni}$ \\
\hline 1 & 83.42 & 4.66 & 0.19 & 3.75 & 0.00 & 7.52 & 0.47 \\
\hline 2 & 38.13 & 0.00 & 0.32 & 10.60 & 0.16 & 50.71 & 0.08 \\
\hline 3 & 84.32 & 3.70 & 0.17 & 2.32 & 0.19 & 9.29 & 0.00 \\
\hline 4 & 19.83 & 0.00 & 0.23 & 13.02 & 0.21 & 66.33 & 0.39 \\
\hline 5 & 81.18 & 3.42 & 0.25 & 2.63 & 0.37 & 12.16 & 0.00 \\
\hline
\end{tabular}

An analysis of the adhesion of the coating on $\mathrm{X} 105 \mathrm{CrMo} 17$ steel following hybrid processing consisting of plasma nitriding and deposition of a carbon coating (PN370-C) was carried out by means of the Scratch Test. Fig. 4 shows a record of the parameters measured during the trial, which include the normal force, the friction coefficient, and acoustic emission as a function of the applied force and the length of the scratch, while Fig. 5 shows a post-test photo of the scratch taken with an optical microscope. 
The moving diamond tip exerts an increasingly greater force on the coating and substrate, but does not cause visible plastic deformation of the coating. At a critical load of $3.11 \mathrm{~N}$, the coating cracked and lost adhesion with the substrate at the same time. The carbon coating is then "smoothered" over the surface of the sample, and crumbling of the coating takes place in the direct vicinity of the scratch. Before cracking, the coefficient of friction oscillated around 0.01 to 0.13 . Further increase of the coefficient of friction occurred when the load exceeded $6.4 \mathrm{~N}$ and reached a value of up to 0.23 at a load of $10 \mathrm{~N}$. Generally speaking, the coefficient of friction did not increase significantly after the coating lost its integrity. It continued to work as a sliding layer (solid grease). It can therefore be said that the carbon coating, even after being damaged, retains its favourable tribological properties. Meanwhile the picture of the course of the scratch is somewhat puzzling. In it, we can see that in some places, the coating was completely removed (Fig. 5), and the coefficient of friction corresponding to these areas, did not undergo any significant change (Fig. 4). The coating was most probably removed after the scratching process.

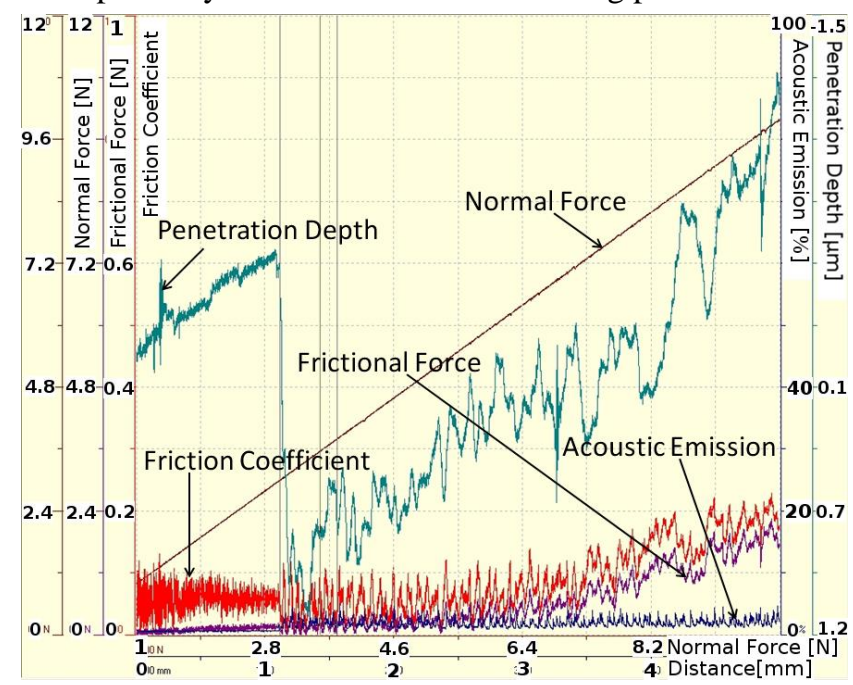

Fig. 4. A record of the measured parameters during the test of adhesion of the coating to the plasma nitrided substrate (PN370-C)

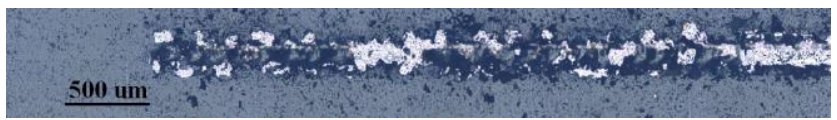

Fig. 5. Scratching of the coating deposited on the nitrided layer (PN370-C); 20x magnification

A record of the parameters measured during the test of adhesion of the carbon coating to $\mathrm{X} 105 \mathrm{CrMo} 17$ steel in initial state (IS-C) is shown in Fig. 6. A photo of the scratch made using an optical microscope is illustrated in Fig. 7.

In the case of the carbon coating formed on steel in initial state (IS-C), deformation of the substrate along with the carbon coating is observed from the very beginning. In the initial stage of scratch formation, before the coating began to chip, no cracks appeared (Fig. 7), but thin "streaks" were visible, which increased in number along with load intensity. These "streaks" may be associated with chromium carbides found in the substrate of X105CrMo17 steel, which could have been pulled out. Cohesion of the coating was lost at a critical load of $11.72 \mathrm{~N}$. The friction coefficient, in the initial phase, up to the point where the chromium carbide was most probably removed, did not exceed a value of 0.1 . After the first peeling of the coating, the coefficient changed its value in the range from 0.1 to 0.2 . Such fluctuations of the friction coefficient may have something to do with the chipping of the carbon coating. More specifically, in the areas where the coating did not peel, the coefficient of friction is low, while in areas where it did, the coefficient of friction is high. Later, the coefficient stabilised at 0.15 until the coating completely came off $(37.3 \mathrm{~N})$ and, as a result, there was a sharp increase in the coefficient to a value of ca. 0.6. Its sharp fall in the final stage of scratching to a value of 0.15 , is also surprising.

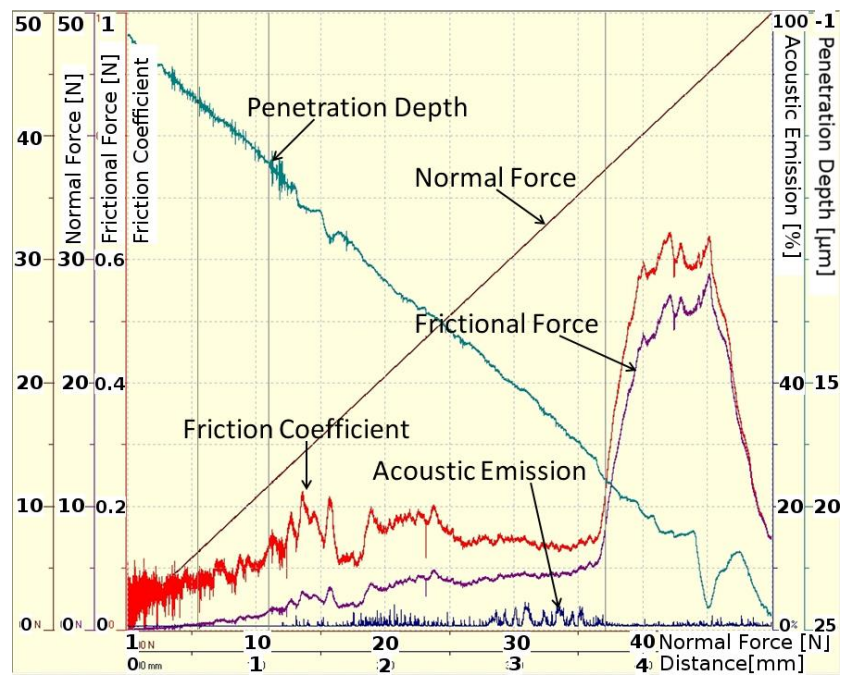

Fig. 6. A record of the parameters measured during the test of adhesion of the coating to the steel substrate in initial state (IS-C)

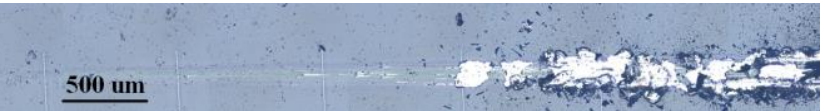

Fig. 7. Scratching of the coating deposited on steel in initial state (IS-C); 20x magnification

Two scratch tests (PN370-C and IS-C) show a different course of coating degradation. In the first case (PN370-C), we are dealing with a hard nitrided layer with a flexible carbon coating on top of it. For this reason, the scratching process can be described as follows. At first, there is no penetration of the tip nor any sign of a scratch (the hard nitrided layer withstands small loads, which do not exceed the yield strength). Then the carbon coating suddenly cracks and chips, as a result of which the tip subsides. A different process is observed in the case of steel in initial state, on which a carbon coating is produced (IS-C). In this case, we are dealing with a substrate which has a lower hardness than the nitrided layer, on which a flexible carbon coating is produced. Therefore, by analysing the picture of this scratched sample, the scratch mark is seen right from the beginning, and the tip subsides deeper into the coating as the load increases. This indicates that the substrate becomes deformed and along with it so does the carbon coating. In the first situation, the carbon coating chipped off at a load of $3.11 \mathrm{~N}$ (PN370-C), while in the second, at $11.72 \mathrm{~N}$ (IS-C). A three times higher 
critical load for the carbon coating formed on steel in initial state is indicative of much better adhesion of the carbon coating to $\mathrm{X} 105 \mathrm{CrMo} 17$ steel than to the nitrided layer formed on the same substrate. Theoretically speaking, the carbon coating formed on initial state steel should chip at a lower load due to decreased substrate hardness, which in the course of deformation, causes the coating also to deform and submits it to greater tension. Despite the fact that the carbon coatings (IS-C, PN370-C) were formed in identical conditions, their structure and properties are not identical to each other. As observed earlier, the carbon coating formed on steel in initial state (IS-C) had much fewer defects and a lower porosity. Each defect in the coating is a discontinuity, thanks to which the initiation of a crack can occur much more easily. This probably had a great impact on the adhesion of the coating, and as a result, on the final result of the critical load, at which the carbon coating began to peel. Zhang,et al. [10] observed a slightly different nature of damage of the DLC coating produced via the filtered cathode vacuum arc (FCVA) method on the unhardened surface of AISI 316L steel and Ti6Al4V alloy. Scaling of the DLC coating, however without plastic deformation, was observed on the austenitic steel substrate at the very beginning of load application (ca. $1 \mathrm{~N}$ ), which was indicative of very poor coating adhesion. In the case of the substrate made of titanium alloy, scaling was observed at a load of approximately $3 \mathrm{~N}$. Based on the authors' own findings and the results of other researchers' work it is concluded that the type and the properties of the substrate the carbon coatings form on play a very important role. In addition, the coatings produced in glow-discharge conditions are characterised by relatively good adhesion to the substrate compared to DLC coatings produced using other, conventional methods.

A change in the coefficient of friction as a result of the increasing number of rotations of the corundum ball on the examined surfaces at a load of $10 \mathrm{~N}$ is shown in Fig. 8.

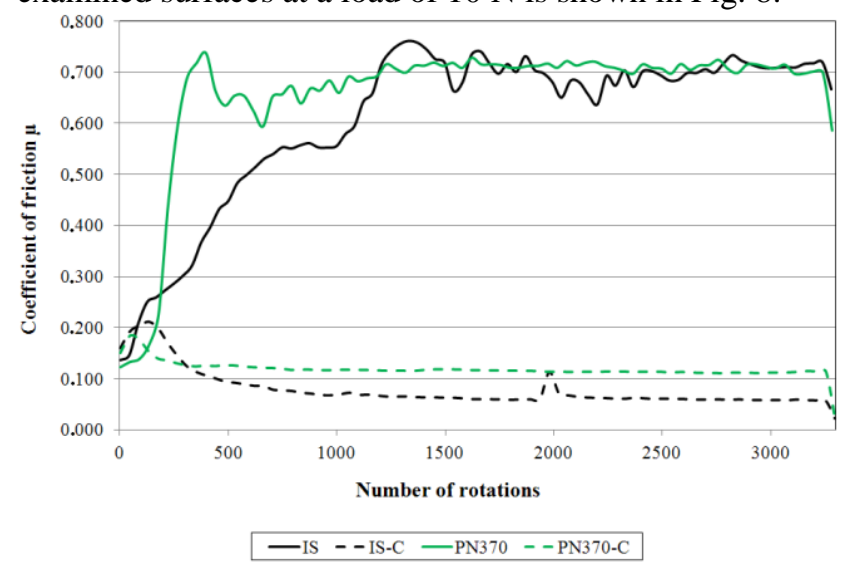

Fig. 8. Diagram of the dependency between the friction coefficient and the number of rotations at a load of $10 \mathrm{~N}$

The final coefficient of friction of the unprocessed $\mathrm{X} 105 \mathrm{CrMo} 17$ steel (IS) and glow-discharge plasma nitrided steel (PN370) was similar and amounted to ca. 0.7 (Fig. 8), whereas both of the samples with the carbon coating were characterised by a very stable and low coefficient of friction. The coefficient for the coating deposited on the nitrided steel (PN370-C) amounted to ca.
0.1 while its value for the coating produced on the steel in initial state (IS-C) was 0.06. During the first rotations, wearing-in takes place and the value of the coefficient increases to ca. 0.2, following which the coefficient decreases and stabilises to its final value. The carbon coating formed on the steel in initial state (IS-C) lowers the friction coefficient over 10 times.

A coefficient value of up to 0.1 is typical for DLCtype carbon coatings obtained via different methods. Yang, et al. [11], who used the ,ball-on-plate" method under a load of $5 \mathrm{~N}$ and using a WC + Co ball as a counter-sample, achieved a friction coefficient of 0.1 for a DLC coating produced via the PECVD method, whereas for a coating containing an admixture of silicon, the coefficient reached a value of 0.05 . Similar results were obtained by Yamamoto, et al. [12] who studied a DLC coating produced using a multicathode unbalanced magnetron (UBM) sputtering device. They conducted tests in distilled water via the "ball-on-plate" method under a load of $5 \mathrm{~N}$ employing a ball made of steel. In turn, Zhang, et al. [13] achieved a friction coefficient of 0.08 in tests conducted in dry air conditions employing a $\mathrm{SiC}$ ball under a load of $1 \mathrm{~N}$, carried out on DLC coatings produced in a thermalelectron excited plasma CVD deposition system.

The image, depth and width of the wear following the "ball-on-disk" test at a load of $10 \mathrm{~N}$ is shown in Table 4. The steel after plasma nitriding at $370{ }^{\circ} \mathrm{C}$ (PN370), shows much lower depth and width of wear compared to the $\mathrm{X} 105 \mathrm{CrMo} 17$ steel in initial state (IS). The steel with a carbon coating are characterised by very low wear depth values reaching as little as $0.02 \mu \mathrm{m}$ (IS-C). The width of the wear is also lower than all the others and amounts to $155 \mu \mathrm{m}$. The samples with the carbon coatings are characterised by a very low friction coefficient and barely visible wear marks as seen after the "ball-on-disk" test. The results prove that the carbon coating is very resistant to wear by friction. The depth of wear of the carbon coating (IS-C) is over 100 times smaller than the depth of wear of steel in initial state (IS) (Table 4).

The better adhesion of the carbon coating to the steel in initial state than to the nitrided layer does not translate into significantly better resistance to wear by friction as shown in the "ball-on-disk" test conducted at a load of $10 \mathrm{~N}$. The corundum ball used during the wear test is of a much greater diameter than the tip used in the scratch test, that is why pressure is applied onto a much greater surface area, which results in lower tension within the coating.

By analysing the anodic polarisation curves, it is observed that the corrosion resistance of the carbon coating formed on nitrided steel (PN370-C) is superior (Fig. 9). Such processed steel has the lowest corrosion current density $i_{\text {corr }}$ and the highest corrosion potential $E_{\text {corr }}$ as a well as high polarisation resistance $R_{\text {pol }}$. Comparing the carbon coating formed on $\mathrm{X} 105 \mathrm{CrMo} 17$ steel in initial state (IS-C) with unprocessed steel (Table. 5) it is concluded that the corrosion potential $E_{\text {corr }}$ of these samples is almost identical, whereas the corrosion current density $i_{\text {corr }}$ of the coating is the lowest (Tab. 5). Wang, et al. [14] achieved very similar $E_{\text {corr }}, i_{\text {corr }}$ and $R_{\text {pol }}$ results for DLC coatings produced on M2 steel via the PECVD method compared to the results achieved for coatings that 
have been produced in this project using glow-discharge nitriding methods.

Table 4. Image showing wear, as well as the depth and width of wear after the "ball-on-disk" test

\begin{tabular}{|c|c|c|c|}
\hline 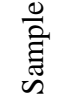 & Images of the wear & $\begin{array}{l}\text { Depth of the } \\
\text { wear, } \mu \mathrm{m}\end{array}$ & $\begin{array}{l}\text { Width of the } \\
\text { wear, } \mu \mathrm{m}\end{array}$ \\
\hline$\cong$ & & 2.54 & 1088 \\
\hline $\begin{array}{l}U \\
\tilde{n}\end{array}$ & & 0.02 & 155 \\
\hline 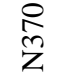 & & 1.6 & 865 \\
\hline 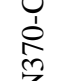 & & 0.06 & 156 \\
\hline
\end{tabular}

The dielectric properties of the coatings, i.e. their high polarisation current, are indicative of the heterogeneity and integrity of DLC coatings, which guarantees their low reactivity when subjected to electrochemical corrosion.

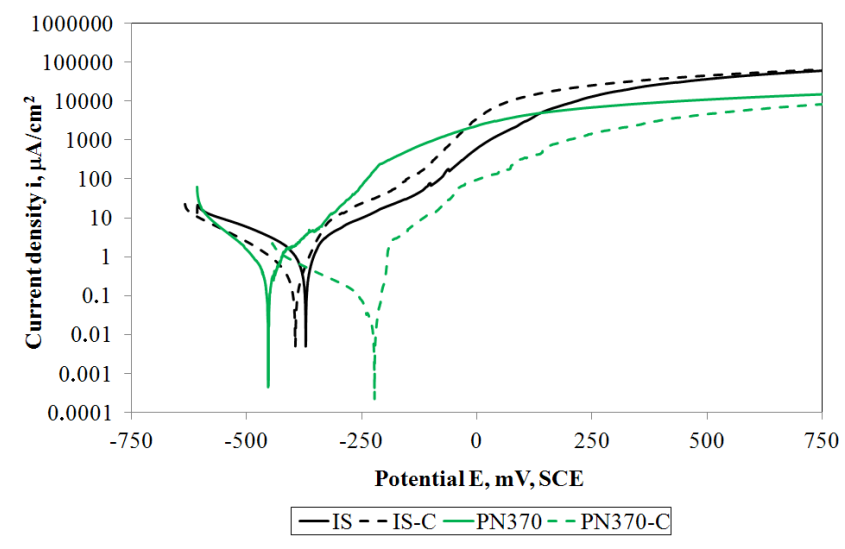

Fig. 9. Polarisation curves for $\mathrm{X} 105 \mathrm{CrMo} 17$ steel in initial state and following surface treatment processes

Table 5. Corrosion potential, corrosion current density and polarisation resistance calculated after the corrosion resistance test conducted using the potentiodynamic method

\begin{tabular}{|c|c|c|c|}
\hline Sample & $E_{\text {corr }}, \mathrm{mV}$ & $i_{\text {corr }}, \mu \mathrm{A} / \mathrm{cm}^{2}$ & $R_{\text {pol }}, \mathrm{kOhm} * \mathrm{~cm}^{2}$ \\
\hline IS & -371 & 0.9 & 20.1 \\
\hline IS-C & -395 & 0.3 & 50.6 \\
\hline PN370 & -453 & 0.6 & 34.6 \\
\hline PN370-C & -282 & 0.1 & 154.3 \\
\hline
\end{tabular}

It would seem that the carbon coating obtained on steel in initial state (IS-C), characterised by lower roughness and fewer defects, should undergo a slower corrosion process that the coating deposited on the nitrided layer. However, it is the substrate structure, which the carbon coating was applied on, which appears to be more important.

\section{CONCLUSIONS}

1. The hybrid method used in processing the surface of $\mathrm{X} 105 \mathrm{CrMo} 17$ steel consisting of nitriding in lowtemperature plasma followed by application of a carbon coating effectively improves: the coefficient of friction, resistance to wear by friction, corrosion resistance, compared to steel in initial state.

2. A much higher critical load in the scratch test for the carbon coating formed on steel in initial state is indicative of much better adhesion of the carbon coating to X105CrMo17 steel than to the nitrided layer formed on the same substrate.

3. The carbon coating produced on $\mathrm{X} 105 \mathrm{CrMo} 17$ steel in initial state, even after being damaged during the scratch test, retains its favourable tribological properties, because it continued to work as a solid grease.

4. The friction coefficient measured by the "ball-ondisk" method for the coating deposited on the nitrided steel amounted to ca. 0.1 , while its value for the coating produced on the steel in initial state was 0.06 , which is at least ten times lower than the friction coefficient of steel in initial state and after nitriding.

5. The corrosion resistance of the carbon coating formed on nitrided steel is characterized by the lowest corrosion current density $i_{\text {corr }}$, the highest corrosion potential $E_{\text {corr }}$ and the highest polarisation resistance $\mathrm{R}_{\mathrm{pol}}$ compared to the carbon coating formed on $\mathrm{X} 105 \mathrm{CrMo} 17$ steel in initial state.

6. During the deposition process, the coating replicates the surface of the substrate.

7. The surface of the X105CrMo17 steel sample in initial state, on which a carbon coating was produced is characterized by a much smaller number of defects compared to the sample, which was nitrided before the deposition of a carbon coating.

\section{Acknowledgments}

This research work was supported by the National Centre of Research and Development - project No. PBS1/A6/9/2012.

\section{REFERENCES}

1. Donnet, C. Recent Progress on the Tribology of Doped Diamond-like and Carbon Alloy Coatings: a Review Surface \& Coatings Technology 100-101 1998: pp. $180-186$.

2. Robertson, J. Dimond-like Amorphous Carbon Materials Science and Engineering: R: Reports $\quad \mathrm{R} 37$ 2002: pp. 129-281.

3. Liu, C., Yang, D., Qi, M., Deng, X. Advances in DLC Coatings by Hybrid PSII and PECVD as a Barrier to Corrosion in Simulated Body Fluid Journal of Materials Science 40 2005: pp. 5603-5608.

4. Podgornik, B., Hogmark, S., Sandberg, O., Leskovsek, V. Wear Resistance and Anti-sticking Properties of Duplex Treated Forming Tool Steel Wear 254 2003: pp. $1113-1121$. 
5. Hu, J., Chou, Y.K., Thompson, R.G., $\quad$ Burgess, J., Street, S. Characterizations of Nano-crystalline Diamond Coating Cutting Tools Surface \& Coatings Technology 202 2007: pp. $1113-1117$.

6. Eskusson, J., Jaaniso, R., Lust, E. Synthesis of DLC films by PLD from liquid target and dependence of film properties on the synthesis conditions Applied Physics 93 A 2008: pp. $745-749$.

7. Xiao, X., Sheldon, B.W., Konca, E., Lev, L.C., Lukitsch, M.J. The Failure Mechanism of Chromium as the Interlayer to Enhance the Adhesion of Nanocrystalline Diamond Coatings on Cemented Carbide Diamond \& Related Materials 18 2009: pp. 1114-1117.

8. Skolek-Stefaniszyn, E., Kamiński, J., Sobczak, J., Wierzchon, T. Modifying the Properties of AISI 316L Steel by Glow Discharge Assisted Low-Temperature Nitriding and Oxynitriding Vacuum 85 2010: pp. 164-169.

9. Nascimento F.C., Lepienski C.M., Foerster C.E., Assmann A., da Silva S.L.R., de M. Siqueira C.J., Chinelatto A.L. Structural, Mechanical, and Tribological Properties of AISI 304 and AISI 316L Steels Submitted to Nitrogen-Carbon Glow Discharge Journal of Materials Science 44 2009: pp. 1045-1053. http://dx.doi.org/10.1007/s10853-008-3211-z
10. Zhang T.F., Deng Q.Y., Liu B., Wu B.J., Jing F.J., Leng Y.X., Huang N. Wear and Corrosion Properties of Diamond Like Carbon (DLC) Coating on Stainless Steel, CoCrMo and Ti6Al4V Substrates Surface \& Coatings Technology 273 2015: pp. $12-19$.

11. Yang W.J, Choa Y.-H., Sekino T., Shim K.B., Niihara K., Auh K.H. Tribological Evaluation of $\mathrm{Si}-\mathrm{O}$ Containing Diamond-like Carbon Films Surface and Coatings Technology 162 2003: pp. 183-188. http://dx.doi.org/10.1016/S0257-8972(02)00583-2

12. Yamamoto K., Matsukado K. Effect of Hydrogenated DLC Coating Hardness on the Tribological Properties Under Water Lubrication Tribology International 39 2006: pp. $1609-1614$

13. Zhang W., Tanaka A. Tribological Properties of DLC Films Deposited Under Various Conditions Using a Plasma-enhanced CVD Tribology International 37 2004: pp. $975-982$. http://dx.doi.org/10.1016/j.triboint.2004.07.015

14. Wang L., Nie X., Hu X. Effect of Thermal Annealing on Tribological and Corrosion Properties of DLC Coatings Journal of Materials Engineering and Performance 22 2013: pp. 3093-3100.

http://dx.doi.org/10.1007/s11665-013-0585-0 